\title{
Percutaneous Ultrasound-Guided Biopsies in the Evaluation of Thoracic Tumours after PET-CT: A Prospective Diagnostic Study
}

\author{
Jos A. Stigt ${ }^{a} \quad$ Ad H. Oostdijk ${ }^{b} \quad$ James E. Boers ${ }^{c} \quad$ Jan Willem K. van den Berg ${ }^{a}$ \\ Harry J.M. Groen ${ }^{d}$ \\ Departments of a Pulmonology, ${ }^{\mathrm{b}}$ Nuclear Medicine and ${ }^{\mathrm{C}}$ Pathology, Isala Klinieken, Zwolle, and \\ dDepartment of Pulmonology, University Medical Center, Groningen, The Netherlands
}

\section{Key Words}

Computed tomography - Positron-emission tomography •

Thoracic malignancies $\cdot$ Ultrasound-guided biopsy

\begin{abstract}
Background: Lesions detected by positron emission tomography-computed tomography (PET-CT) during the analysis of thoracic tumours are often impalpable at physical examination, and subsequent ultrasound (US) may aid in finding these lesions for pathologic evaluation. Objectives: The success rate of percutaneous US-guided biopsies of palpable and non-palpable lesions and the impact on tumour stage were studied prospectively. Methods: Lesions, significant for diagnosis and disease stage, with metabolic activity on PET-CT and presumed appropriate for percutaneous approach under US guidance were selected for cytologic aspiration or tissue core biopsies. Results: In 127 patients, 134 lesions (subdivided into 24 local thoracic, 74 supraclavicular and 36 distant metastatic lesions) were biopsied percutaneously under US guidance. Malignancy, benign disease and inadequate biopsies were found in 80\% (106/134), 14\% $(19 / 134)$ and $7 \%$ (9/134), respectively. In 55\% (56/102) of patients, biopsies confirmed the disease stage. Fifty-one percent $(18 / 35)$ of distant lesions and $54 \%(43 / 68)$ of supraclavicular lesions were impalpable on physical examination.
\end{abstract}

Conclusions: US-guided biopsies in patients with suspected thoracic malignancy on PET-CT provide an excellent tool for obtaining a pathological diagnosis, leading to a definitive disease stage in over half of the patients.

Copyright $\odot 2011$ S. Karger AG, Basel

\section{Introduction}

2-Fluoro-2-deoxy-D-glucose positron emission tomography (FDG-PET) integrated with computed tomography $(\mathrm{CT})$ provides both anatomic and metabolic information, making it an extremely important tool in characterizing both local thoracic as well as metastatic disease. It has been demonstrated to have a higher diagnostic accuracy than PET or CT alone [1-4]. Therefore, it can be considered the most important imaging tool in the analysis of thoracic tumours. Nevertheless, due to the low specificity of PET, pathological confirmation is necessary to establish a definitive diagnosis and/or to provide a tumour stage [5].

While a careful physical examination is considered standard of care, metastatic lesions are often missed and discovered only on PET. The visualization of both palpable and non-palpable lesions by ultrasound (US) allows for real-time biopsy. This technique enables safe patho-

\section{KARGER}

Fax +4161306 1234

E-Mail karger@karger.ch

www.karger.com
(C) 2011 S. Karger AG, Basel

0025-7931/12/0831-0045\$38.00/0

Accessible online at:

www.karger.com/res
Jos A. Stigt, MD

Department of Pulmonology, Isala Klinieken

Groot Wezenland 20

NL-8011 JW Zwolle (The Netherlands)

E-Mail j.a.stigt@isala.nl 
logic sampling with fine needle aspiration (FNA) or tissue core biopsies (TCB) of thoracic tumours in contact with the thoracic cage but also supraclavicular metastatic disease and various sites of distant metastatic disease.

Pulmonologists in Europe have become increasingly familiar with US imaging as endoscopic and endobronchial US are nowadays established procedures in the diagnosis and staging of lung cancer. Although US-guided percutaneous biopsy and aspiration in the diagnosis of pleural disease are broadly practised by pulmonologists, the technique is seldom applied to other thoracic indications. A recent guideline of the American College of Chest Physicians recommends confirmation of a suspected lung cancer by obtaining tumour cells or tissue with FNA or biopsy if feasible [6]. If pulmonologists become proficient in US-guided biopsy they can expand their role in lung cancer diagnosis and staging.

This study is a prospective analysis of the value of percutaneous US-guided FNA and TCB in patients with PET-CT-suspected thoracic neoplasms as performed by pulmonologists. The evaluating and procedural pulmonologist determined the lesions to be sampled based on their accessibility and visibility by US-guided biopsy and their importance in diagnosis and/or staging. It was hypothesized that US-accessible lesions (no matter if palpable or not) detected on PET-CT will provide a definitive pathological diagnosis and pathological proof of disease stage.

\section{Patients and Methods}

\section{Study Population}

Patients that were selected for US-guided sampling had all undergone PET-CT scans for suspected thoracic tumours. The selection was discussed in meetings of the nuclear physician and pulmonologist and was based on PET-CT results.

The lesions observed on PET-CT that were approached for pathologic US-guided sampling had to fulfill three criteria.

First, they were judged by a pulmonologist to be accessible by US-guided FNA or biopsies (for instance adjacent to the thoracic wall or located in the supraclavicular or axillary region). Second, only lesions with increased FDG uptake were selected. Third, the lesions had to be significant for tumour staging. Preferably, the obtained material delivered a pathological diagnosis and stage verification at once.

If PET-CT showed obvious and extensive metastatic disease, there were occasional deviations from this principle. In these cases, the easiest accessible lesions were approached (for example, some widespread metastasized stage IV tumours were diagnosed according to this strategy with supraclavicular aspirations).

The diagnostic strategy was based on recommendations in the guidelines on the initial diagnosis of lung cancer of the American College of Chest Physicians.
According to legal criteria for medical research, our institutional review board stated that approval was not necessary for this study.

\section{Methods}

PET-CT scans were performed on an integrated PET-CT scanner (GE Discovery ST PET-CT scanner, General Electric, Milwaukee, Wisc., USA).

Percutaneous US-guided FNA was performed by a pulmonologist with a Hitachi probe (EUP-C532) with a EZU-PA532 Hitachi Biopsy attachment and a Hitachi EUB-5500 processor. TCB and FNA were obtained under direct vision.

Needles used were Spinocan $0.9 \times 88 \mathrm{~mm} / 20$ gauge $\times 8 \mathrm{~cm}$ for cytology. For histologic biopsies, Bard core tissue biopsy needles 14 gauge $\times 13 \mathrm{~cm}$ were used with a Bard magnum biopsy instrument (fig. 1).

A local physical examination was performed, before the application of US, to determine if lesions were palpable or not.

All biopsies and aspirations were performed under local anaesthesia of the skin with lidocaine $2 \%$. For local thoracic tumours, specimens were preferentially obtained with core tissue biopsy needles for histologic analysis. Two or 3 TCB were taken as a rule for histologic sampling. Supraclavicular and distant metastatic lesions were usually approached with FNA. Specimens obtained with FNA were smeared on slides for morphologic analysis and deposited in a fixative for immunohistochemical staining in cases where subtyping was necessary. Two to 4 needle passes into each lesion were taken. There was no on-site evaluation of the samples by a pathologist.

The numbers of adequate (enough tissue or material to make a diagnosis as assessed by a pathologist after microscopy) and inadequate biopsies (not enough tissue or material or no accessible tumour or lymph node by US) were counted. In the case of inadequate aspirates or biopsies, CT-guided biopsies, endoscopic biopsies or surgical procedures were performed. When these additional investigations had to be performed, this was considered as a failure of the US procedure. In case such an approach was not feasible, clinical follow-up data were available to substantiate the diagnosis.

Stage categories as defined by the American Joint Committee on Cancer Staging [7] and the sixth edition of the Union Internationale Contre le Cancer [8] were applied.

\section{Results}

Between March 2006 and May 2009, a total number of 127 patients out of 1,056 patients $(12 \%)$ in whom PET-CT was performed to image suspected thoracic malignancies were considered suitable for US-guided biopsies.

In these patients, a total number of 134 lesions were approached for US-guided biopsies (FNA, $\mathrm{n}=107$; TCB, $\mathrm{n}=22$; not detectable with US, $\mathrm{n}=5$ ). In 5 patients, USguided biopsies were performed on more than one lesion (1 patient had 3 biopsies on different lesions and 4 patients had 2 biopsies on different lesions). Table 1 shows the distribution of FNA and TCB in the subcategories lo- 
Fig. 1. Devices used for US-guided aspirations and core tissue biopsies. a Biopsy attachment with a 20 -gauge needle mounted on US probe. b Biopsy attachment with core tissue biopsy needle.
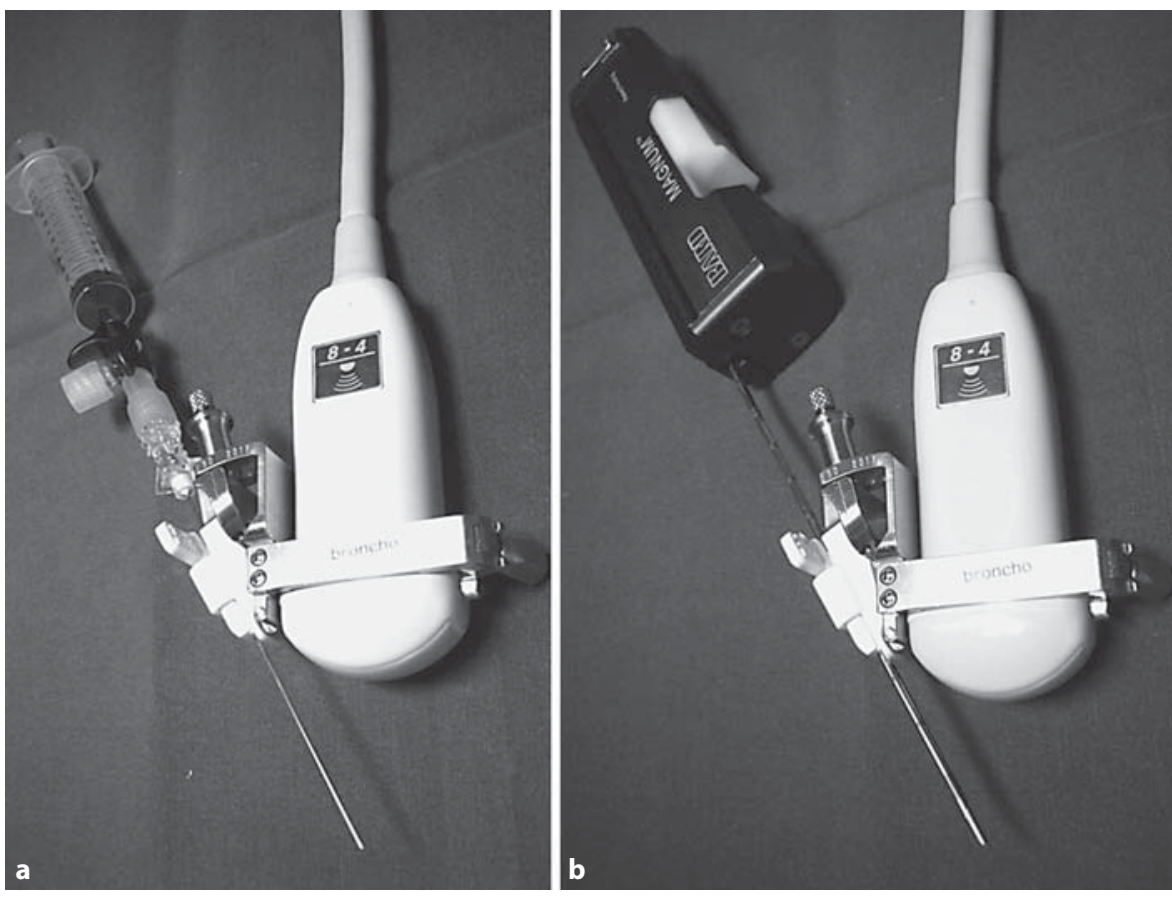

Table 1. US-guided aspirations and biopsies from PET-CT-observed lesions

\begin{tabular}{lcclrrr}
\hline Location & $\mathrm{n}$ & $\begin{array}{l}\text { US-observed } \\
\text { lesions }\end{array}$ & $\begin{array}{l}\text { Lesions not } \\
\text { detectable with US }\end{array}$ & FNA & $\begin{array}{c}\text { TCB } \\
\text { Palpation } \\
\text { performed }\end{array}$ & $\begin{array}{l}\text { Palpation } \\
\text { negative }\end{array}$ \\
\hline Local thoracic lesions & 24 & $22(92)$ & $2(8)$ & 4 & 18 & NA \\
Supraclavicular nodes & 74 & $71(96)$ & $3(4)$ & 71 & 0 & $68(92)$ \\
Distant lesions & 36 & $36100)$ & 0 & 32 & 4 & $35(97)$ \\
\hline Total & 134 & $129(96)$ & $5(4)$ & 107 & 22 & \\
\hline
\end{tabular}

Figures in parentheses are percentages. NA = Not applicable.

Table 2. Pathologic results of US-guided aspirations and biopsies from PET-CT-observed lesions

\begin{tabular}{lllllr}
\hline Location & $\mathrm{n}$ & $\begin{array}{l}\text { Inadequate } \\
\text { biopsies }^{1}\end{array}$ & $\begin{array}{l}\text { Benign } \\
\text { diagnosis }\end{array}$ & $\begin{array}{l}\text { Malignant } \\
\text { diagnosis }\end{array}$ & $\begin{array}{c}\text { Stage-defining } \\
\text { lesions }\end{array}$ \\
\hline Local thoracic lesions & 24 & $5(21)$ & $2(8)$ & $17(71)$ & $9(53)$ \\
Supraclavicular nodes & 74 & $3(4)$ & $7(9)$ & $64(86)$ & $32(50)$ \\
Distant lesions & 36 & $1(3)$ & $10(28)$ & $25(69)$ & $20(80)$ \\
\hline Total & 134 & $9(7)$ & $19(14)$ & $106(80)^{3}$ & $61(58)$ \\
\hline
\end{tabular}

Figures in parentheses are percentages.

${ }^{1}$ Inadequate biopsies are failures to find PET-CT-observed lesions by US and biopsies without adequate material as assessed by the pathologist. ${ }^{2}$ Percentage of malignant lesions that determine the tumour stage. ${ }^{3} 106$ lesions containing malignant tissue were biopsied in 102 patients. In 4 patients, 2 malignant lesions were biopsied. 
Table 3. US-guided aspirations and biopsies from 106 PET-CTobserved lesions in 102 patients that lead to pathologically confirmed malignant diagnoses

\begin{tabular}{lccc}
\hline & $\begin{array}{l}\text { Local tho- } \\
\text { racic lesions }\end{array}$ & $\begin{array}{l}\text { Supraclavic- } \\
\text { ular nodes }\end{array}$ & $\begin{array}{l}\text { Distant } \\
\text { lesions }\end{array}$ \\
\hline NSCLC & 7 & 45 & 16 \\
SCLC & 0 & 13 & 2 \\
LCNEC & 1 & 2 & 1 \\
Sarcoma & 1 & 2 & 0 \\
Mesothelioma & 5 & 0 & 1 \\
Non-pulmonary metastasis & 1 & 1 & 0 \\
Malignant lymphoma & 0 & 1 & 5 \\
Thymoma & 2 & 0 & 0 \\
\hline Total & 17 & 64 & 25 \\
\hline
\end{tabular}

SCLC $=$ Small cell lung cancer; LCNEC = large cell neuroendocrine cancer.

Table 4. Subtyping results of NSCLC in FNA and TCB based on morphologic and immunohistochemical analysis

\begin{tabular}{lcl}
\hline Subtypes & FNA & TCB \\
\hline Local thoracic lesions & & \\
$\quad$ Adenocarcinoma & 2 & 0 \\
Squamous cell carcinoma & 2 & 1 \\
$\quad$ Not differentiated & 1 & 1 \\
Subtotal & 5 & 2 \\
\hline Supraclavicular lesions & & \\
Adenocarcinoma & 30 & 0 \\
Squamous cell carcinoma & 11 & 0 \\
Large cell carcinoma & 1 & 0 \\
Not differentiated & 1 & 0 \\
Not applicable & 2 & 0 \\
Subtotal & 45 & 0 \\
\hline Distant lesions & & \\
Adenocarcinoma & 10 & 2 \\
Squamous cell carcinoma & 3 & 0 \\
Not differentiated & 1 & 0 \\
Subtotal & 14 & 2 \\
\hline Total & 64 & 4
\end{tabular}

${ }^{1}$ One patient was known with a pulmonary adenocarcinoma 2 years before, and in 1 patient, bronchial biopsies already showed a primary adenocarcinoma. cal thoracic, supraclavicular and distant lesions (distant lesions are metastatic lesions other than mediastinal or supraclavicular lesions).

Successful US-guided biopsies were performed in $93 \%$ $(125 / 134)$ of lesions.

Seven percent (9/134) of US-guided biopsies were considered inadequate either because PET-CT-observed lesions could not be detected by US $(\mathrm{n}=5)$ or because biopsies contained inadequate material $(\mathrm{n}=4)($ table 2$)$.

\section{Palpation}

At physical examination (performed after PET-CT), palpation of lesions was recorded in $92 \%(68 / 74)$ of patients with supraclavicular lesions and in 94\% (34/36) of patients with distant lesions. Table 1 shows that $54 \%$ of examined supraclavicular and $51 \%$ of examined distant lesions were not palpable (as expected, local thoracic disease was not palpable in any of the patients).

\section{Malignancy by US-Guided Biopsies}

Overall, malignancy was confirmed in $80 \%(106 / 134)$ of US-guided biopsies in PET-CT-positive lesions with a predominant representation of non-small cell lung cancer (NSCLC; 51\%, 68/134) as shown in table 3. Subtypes of NSCLC in FNA and TCB are shown in table 4. In 3 FNA and 1 TCB, subtyping was not possible, and in 2 FNA, subtyping was not carried out because a histological diagnosis was already available. Local thoracic USguided biopsies were positive for malignancy in $71 \%$ (17/24) of lesions, supraclavicular US-guided biopsies in $86 \%(64 / 74)$ of lesions and distant US-guided biopsies in $69 \%(25 / 36)$ of lesions (table 2$)$. Positive predictive values to find malignancy by US-guided punctures in thoracic, supraclavicular and distant lesions observed with PETCT were 77,90 and $69 \%$, respectively.

\section{Benign Disease}

Benign diagnoses were obtained in $14 \%$ (19/134) of PET-CT-positive lesions. In $8 \%(2 / 24)$ of local thoracic lesions, a benign diagnosis was derived. Supraclavicular US-guided biopsies showed benign disease in 10\% (7/74) of biopsied lesions, and distant US-guided biopsies showed benign disease in 28\% (10/36) of lesions. Benign diagnoses are listed in table 5.

\section{Inadequate Biopsies}

The overall rate of inadequate US-guided biopsies was $7 \%(9 / 134)$, as demonstrated in table 2 . Inadequate USguided biopsies were performed in $21 \%$ (5/24) of local lesions. One patient had a clinical follow-up of local pleural 
Table 5. US-guided aspirations and biopsies from PET-CT-observed lesions that lead to pathologically confirmed benign diagnoses

\begin{tabular}{llll}
\hline & $\begin{array}{l}\text { Local tho- } \\
\text { racic lesions }\end{array}$ & $\begin{array}{l}\text { Supraclavic- } \\
\text { ular nodes }\end{array}$ & $\begin{array}{l}\text { Distant } \\
\text { lesions }\end{array}$ \\
\hline $\begin{array}{l}\text { Non-specific reactive } \\
\quad \text { lymph nodes }\end{array}$ & 0 & 6 & 7 \\
Organizing pneumonia & 2 & 0 & 2 \\
Whartin's tumour & 0 & 0 & 3 \\
Sarcoidosis & 0 & 1 & 0 \\
\hline Total & 2 & 7 & 10 \\
\hline
\end{tabular}

broadening after pneumonectomy during 18 months without any sign of progression. Two lesions were biopsied subsequently by surgery ( 1 mesothelioma and $1 \mathrm{ma}-$ lignant lymphoma), and 1 lesion was biopsied under CT guidance (bronchoalveolar carcinoma). In 1 patient, a thoracic tumour could not be detected with percutaneous US, but a diagnosis was obtained by a US-guided biopsy of the left adrenal gland (NSCLC).

Inadequate US-guided biopsies were performed in supraclavicular regions in $4 \%(3 / 74)$ of lesions and in $3 \%$ (1/36) of distant lesions. During a median clinical followup of 1 year (range 7-41 months) of the 3 supraclavicular non-successfully biopsied lesions, no tumour appeared. The distant non-successfully biopsied lesion was lost to follow-up.

\section{Staging of Disease}

In 58\% (61/106) of lesions with a malignant diagnosis, this result confirmed the tumour stage. For local thoracic malignant lesions, supraclavicular malignant lesions and distant malignant lesions, these rates were 53\% (9/17), $50 \%(32 / 64)$ and $80 \%(20 / 25)$, respectively (table 2).

A total number of 106 lesions with malignancy was found in 102 patients ( 2 different malignant lesions were biopsied in 4 patients). A pathological confirmation of tumour stage was achieved in 55\% (56/102) of patients with malignancy. In $45 \%$ (46/102) of patients, the biopsy provided a diagnosis, but the lesions were not confirmative for disease stage. Ten percent (10/102) of patients with malignancy needed additional invasive investigations to confirm disease stage or subtyping of the tumour. The procedures were lymph node excisions and thoracoscopy by surgery $(n=4)$ and endoscopic US with histologic biopsies for immunohistochemical subtyping of malignant lymphomas $(n=1)$, endobronchial US for mediastinal node metastasis $(\mathrm{n}=1)$ and 4 FNAs (in the left adrenal gland, in a coeliac and axillar lymph node, and a cutaneous metastasis, respectively).

For the other 36 patients, additional biopsies were not required. In 26 patients (25\%), PET-CT showed obvious extensive metastatic disease, where confirmation of malignancy seemed not appropriate, 5 patients had mesothelioma, 4 patients had brain metastases, and for 1 patient, the biopsy was obtained to differentiate between progression of 2 different recurrent malignant diseases.

\section{Complications}

There were 2 (1.5\%) complications registered. Both occurred after TCB of a local thoracic lesion. One of the histologic biopsies was complicated by a severe haemoptysis leading to intubation. One of the TCB also contained spleen tissue on pathologic examination without adverse events after the biopsy. No other significant adverse events were noticed.

\section{Discussion}

This study shows that percutaneous US-guided biopsies in the diagnosis and staging of thoracic tumours have a high diagnostic success rate after localization with PETCT. The quality and quantity of cytologic specimen allowed pathologists to specify subtypes of NSCLC in almost all patients.

The high resolution of US for lesions within about 5-10 cm distance from the skin brings many lesions within the scope of US-guided biopsies. For intrapulmonary lesions, this may not be the case due to positional alterations by gravity when CT images in the prone position are used to select lesions for the US-guided approach in the supine position (fig. 2). Other failures of US-guided punctures were due to inaccurate interpretations of PET-CT like brown fatty tissue located at supraclavicular locations and inaccurate pathologic sampling.

\section{Thoracic Lesions}

Although US is a relatively underused diagnostic modality, it provides an accurate localization of chest abnormalities if not surrounded by aerated lung [9]. In this study, the most prominent reason for test failure in local thoracic disease was indeed the inability to image lesions through aerated lung by US. Former studies already demonstrated the benefit of US-guided biopsies after CT imaging. Percutaneous biopsies of pulmonary, pleural or mediastinal lesions in contact with the chest wall under 
Fig. 2. Effect of body position on US visibility of an intrathoracic lesion. Example of problems encountered with the use of US. a Patient in prone position. Lesion in the dorsal left lung adjacent to the thoracic wall. b Same patient lying in supine position for biopsy. The lesion is no longer adjacent to the thoracic wall and becomes invisible for US.
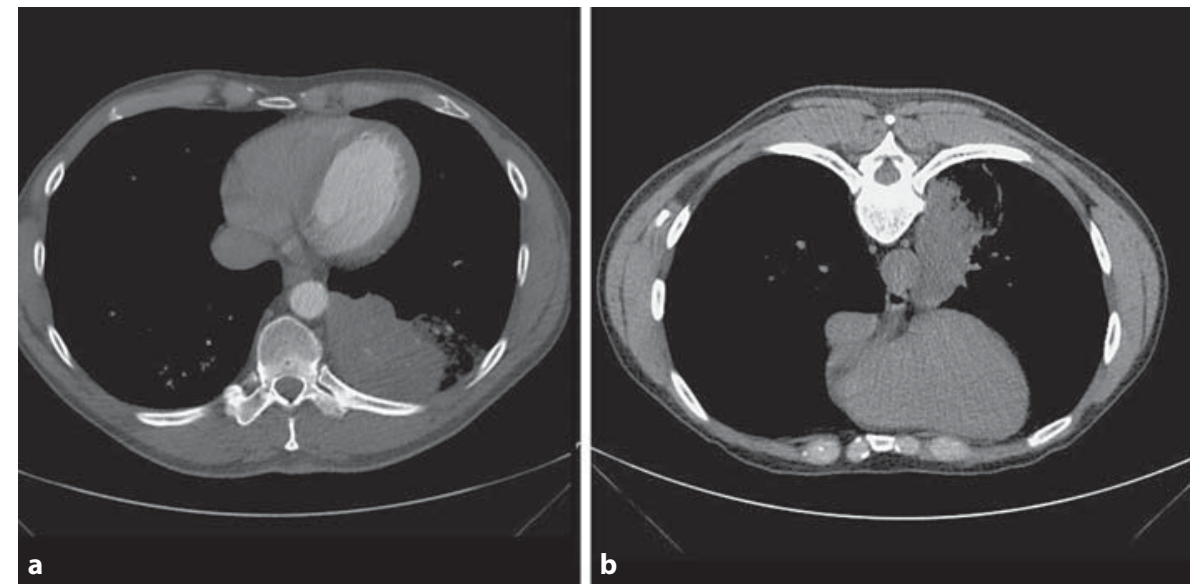

US guidance yielded a diagnosis in $90 \%$ of patients with a malignancy and in $67 \%$ of patients with benign lesions in a study of 124 patients [10]. A high efficacy of US-guided biopsies was reported in 31 out of 34 lesions in the analysis of thoracic tumours [11]. Recently, a diagnostic yield of $>93 \%$ was reported in a single-session sequential approach of mediastinal masses with US-assisted transthoracal FNA (with rapid on-site evaluation) eventually followed by TCB [12].

Even centrally located tumours with post-obstructive collapse or pneumonitis can be safely biopsied with deep passes and an acceptable diagnostic yield of 74\% [13].

Evaluation of local thoracic disease with PET scans has the important advantage to discriminate between active metabolic diseases (inflammatory and malignant) and diseases without increased metabolic activity such as atelectasis, loculated fluid or scar tissue. Lesions without FDG uptake are probably benign and justify a wait and see attitude. Lung cancer is generally characterized by high FDG uptake, but for assessment of the T stage, PET scans have limited value [14]. The variety of possible alternative diagnoses of PET-CT-positive solitary thoracic tumours accounts for the need for tissue. This is demonstrated by the high number of benign and non-primarily pulmonary malignancies found in this study (11 out of 19 diagnoses).

\section{Supraclavicular Lymph Nodes}

Supraclavicular nodes are frequently involved in lung cancer and define stage IIIB disease. In this study, we focused on PET-CT-positive supraclavicular findings and demonstrated malignancy in the majority of patients suspected to have a thoracic neoplasm, especially NSCLC.
PET-CT has a diagnostic accuracy of $71 \%$ in detecting non-palpable supraclavicular lymph node metastasis as was demonstrated in a group of 32 patients with NSCLC [15]. In our study, accuracy was $85 \%$. The sensitivity of palpation of supraclavicular node metastasis in lung cancer is significantly lower than with US or CT. This was illustrated by a study that demonstrated malignancy with US-guided FNA in $8 \%$ of patients with suspected and potentially operable lung cancer without palpable lymph nodes [16]. A study of 117 patients analysed for lung cancer confirmed this low sensitivity of palpation compared to US or CT and demonstrated that only markedly enlarged metastases were palpable [17].

In patients with proven $\mathrm{N} 2$ or $\mathrm{N} 3$ disease, enlarged but non-palpable supraclavicular lymph nodes (on CT) contained metastatic disease in even $45.5 \%$ of patients [18]. This study confirms the added value of US in detecting enlarged but non-palpable supraclavicular lymph nodes.

\section{Distant Metastatic Disease}

An important feature of FDG-PET is the ability to detect distant metastatic disease.

In about $8-10 \%$ of resectable patients with NSCLC and in 18 and $24 \%$ of stage II and III patients who were staged conventionally (with CT scan, bone scans and ultrasonography), PET scan detected distant metastatic disease [19-21].

With US, many metastatic sites can be reached percutaneously if lesions are not surrounded by air or covered by bony structures. The ability to visualize lesions is furthermore dependent on the size of lesions, tissue characteristics and interfaces, distance to transducer and sensitivity of equipment. 
In this study, US-guided biopsies were performed in axillary, retromandibular, retroauricular, intercostal, soft tissue, skin and osseous lesions. Half the patients (51\%) had non-palpable lesions. The value of US guidance to obtain material for pathologic verification of PET-CTpositive lesions is emphasized in this study.

\section{Staging with US-Guided Biopsies}

For more than half of the patients with malignancy in this study, the minimally invasive approach with an US approach confirmed diagnosis and disease stage at one time. Endoscopic investigations, often performed as a routine practice in the analysis of thoracic tumours, are generally considered unpleasant and can be omitted if percutaneous US-guided biopsies confirm malignancy.

Diagnostic tests to obtain pathologic specimen should be chosen with a minimal burden to the patient but with maintenance of high-quality diagnostic characteristics [5]. US-guided biopsies match these qualities, as demonstrated in this study.

\section{Palpation of Lesions}

A careful physical examination is one of the first parts of the diagnostic workup of patients with a suspected thoracic malignancy. In this study, more than half the lesions were not palpable, although the physician was aware of the results of the PET-CT. With the use of US guidance, the lesions could be detected and biopsied very effectively. On the contrary, when lesions are palpable, the use of US guidance diminishes the chance of inadequate biopsies in thyroid nodules when compared with palpationguided biopsies [22]. Therefore, the use of US is recommended in both situations.

\section{Limitations}

Although the study is a prospective analysis of USguided biopsy results, there was no well-defined selection of patients according to protocol criteria. Patients were selected on clinical criteria that work sufficiently in daily practice but influence the outcome of results unequivocally. At the start of a new technique, there is a tendency to select lesions with high pretest probability for successful biopsies. When experience increases, biopsies of more difficult lesions will be attempted but will also lead to increasing failure rates.

A criterion to select lesions for percutaneous US-guided biopsies was the uptake of FDG. Small lesions, which do not have enough tracer to be seen on PET-CT were not selected for US-guided biopsies and could therefore be missed for staging.

In conclusion, this study demonstrates that US-guided percutaneous biopsies increase the pathological outcome in the workup of thoracic tumours after PET-CT. PET-CT in combination with subsequent US-guided biopsy provides a definitive diagnosis and tumour stage in the majority of patients and can be performed safely.

Percutaneous US-guided biopsies expand the diagnostic capability of pulmonologists in diagnosing and staging thoracic tumours.

\section{Financial Disclosure and Conflicts of Interest}

The authors declare no conflict of interest.

\section{References}

-1 Antoch G, Stattaus J, Nemat AT, Marnitz S, Beyer T, Kuehl H, Bockisch A, Debatin JF, Freudenberg LS: Non-small cell lung cancer: dual-modality PET/CT in preoperative staging. Radiology 2003;229:526-533.

2 Cerfolio RJ, Ojha B, Bryant AS, Raghuveer V, Mountz JM, Bartolucci AA: The accuracy of integrated PET-CT compared with dedicated PET alone for the staging of patients with nonsmall cell lung cancer. Ann Thorac Surg 2004;78:1017-1023.

-3 Lardinois D, Weder W, Hany TF, Kamel EM, Korom S, Seifert B, von Schulthess GK, Steinert HC: Staging of non-small-cell lung cancer with integrated positron-emission tomography and computed tomography. N Engl J Med 2003;348:2500-2507.
4 Shim SS, Lee KS, Kim BT, Chung MJ, Lee EJ, Han J, Choi JY, Kwon OJ, Shim YM, Kim S: Non-small cell lung cancer: prospective comparison of integrated FDG PET/CT and $\mathrm{CT}$ alone for preoperative staging. Radiology 2005;236:1011-1019.

5 Silvestri GA, Gould MK, Margolis ML, Tanoue LT, McCrory D, Toloza E, Detterbeck F: Noninvasive staging of non-small cell lung cancer: ACCP evidence-based clinical practice guidelines (2nd edition). Chest 2007;132: 178S-201S

6 Rivera MP, Mehta AC: Initial diagnosis of lung cancer: ACCP evidence-based clinical practice guidelines (2nd edition). Chest 2007;132:131S-148S
7 Greene FL, Compton CC, Fritz AG, Shah JP, Winchester DP (eds): American Joint Committee on Cancer Staging Atlas. Chicago, Springer, 2006, pp 167-176.

8 Sobin LH, Wittekind CL (eds): UICC: TNM Classification of Malignant Tumors, ed 6. New York, John Wiley \& Sons, 2002.

9 Middleton WD, Teefey SA, Dahiya N: Ultrasound-guided chest biopsies. Ultrasound Q 2006;22:241-252.

10 Ikezoe J, Morimoto S, Arisawa J, Takashima S, Kozuka T, Nakahara K: Percutaneous biopsy of thoracic lesions: value of sonography for needle guidance. Am J Roentgenol 1990; 154:1181-1185. 
11 Sheth S, Hamper UM, Stanley DB, Wheeler $\mathrm{JH}$, Smith PA: US guidance for thoracic biopsy: a valuable alternative to $\mathrm{CT}$. Radiology 1999;210:721-726.

$>12$ Koegelenberg CF, Diacon AH, Irusen EM, von Groote-Bidlingmaier F, Mowlana A, Wright CA, Louw M, Schubert PT, Bolliger CT: The diagnostic yield and safety of ultrasound-assisted transthoracic biopsy of mediastinal masses. Respiration 2011;81:134141.

13 Koegelenberg CF, Bolliger CT, Irusen EM, Wright CA, Louw M, Schubert PT, Diacon $\mathrm{AH}$ : The diagnostic yield and safety of ultrasound-assisted transthoracic fine-needle aspiration of drowned lung. Respiration 2011; 81:26-31.

14 Vansteenkiste J, Fischer BM, Dooms C, Mortensen J: Positron-emission tomography in prognostic and therapeutic assessment of lung cancer: systematic review. Lancet Oncol 2004;5:531-540.

15 Sung YM, Lee KS, Kim BT, Kim S, Kwon OJ, Choi JY, Yang SO: Nonpalpable supraclavicular lymph nodes in lung cancer patients: preoperative characterization with ${ }^{18} \mathrm{~F}$-FDG PET/CT. Am J Roentgenol 2008;190:246252.
16 Sihoe AD, Lee TW, Ahuja AT, Yim AP: Should cervical ultrasonography be a routine staging investigation for lung cancer patients with impalpable cervical lymph nodes? Eur J Cardiothorac Surg 2004;25: 486-491.

17 van Overhagen $\mathrm{H}$, Brakel $\mathrm{K}$, Heijenbrok MW, van Kasteren JHLM, van de Moosdijk CNF, Roldaan AC, van Gils AP, Hansen BE: Metastases in supraclavicular lymph nodes in lung cancer: assessment with palpation, US, and CT. Radiology 2004;232:75-80.

18 Kumaran M, Benamore RE, Vaidhyanath R, Muller S, Richards CJ, Peake MD, Entwisle JJ: Ultrasound guided cytological aspiration of supraclavicular lymph nodes in patients with suspected lung cancer. Thorax 2005; 60:229-233.
19 MacManus MP, Hicks RJ, Matthews JP, Hogg A, McKenzie AF, Wirth A, Ware RE, Ball DL: High rate of detection of unsuspected distant metastases by PET in apparent stage III non-small-cell lung cancer: implications for radical radiation therapy. Int J Radiat Oncol Biol Phys 2001;50:287293.

20 Pieterman RM, van Putten JWG, Meuzelaar JJ, Mooyaart EL, Vaalburg W, Koeter GH, Fidler V, Pruim J, Groen HJM: Preoperative staging of non-small-cell lung cancer with positron-emission tomography. $\mathrm{N}$ Engl Med 2000;343:254-261.

21 Stroobants SG, D'Hoore I, Dooms C, De Leyn PR, Dupont PJ, De Wever W, De GT, Verschakelen JA, Mortelmans LA, Vansteenkiste JF: Additional value of whole-body fluorodeoxyglucose positron emission tomography in the detection of distant metastases of non-small-cell lung cancer. Clin Lung Cancer 2003;4:242-247.

-22 Can AS, Peker K: Comparison of palpationversus ultrasound-guided fine-needle aspiration biopsies in the evaluation of thyroid nodules. BMC Res Notes 2008;1:12. 